\title{
Temperature parameters in the combustion chambers of CUMMINS KTA-50 engines operat- ing on various fuels under different fuel con- sumption rates
}

\author{
Georgiy Dubov ${ }^{1 *}$, Alexander Bogomolov ${ }^{1,2}$, Sergey Azikhanov ${ }^{1,2}$, Pavel Strelnikov ${ }^{1}$, and \\ Sergey Nokhrin ${ }^{3}$ \\ ${ }^{1}$ T.F. Gorbachev Kuzbass State Technical University, Department of Mechanical Engineering \\ Technology, 28 Vesennyaya st., Kemerovo, the Russian Federation \\ ${ }^{2}$ Kutateladze Institute of Thermophysics SB RAS, Academician Lavrentyev Prospect, 1, \\ Novosibirsk, the Russian Federation \\ ${ }^{3}$ «TekhnoEco» LLC, 11 Azovskaya St., Prokopyevsk, the Russian Federation
}

\begin{abstract}
The issue of a comparative study of fuel consumption and temperature characteristics of gas-diesel BelAZ 75131 mining dump trucks equipped with an on-board cryogenic fuel system and hauling rock mass at the Kuzbass open-pit coal mine is considered in the article. A brief analysis of the efficiency of using liquefied natural gas (LNG) methane - as a motor fuel for mining dump trucks is carried out. It is noted that the use of LNG fuel for heavy-duty dump trucks is one of the most promising ways to improve the environmental and economic performance during the operation of this type of mining equipment. The technique and instrumental base for conducting research are presented. The relationship between natural ratios of diesel fuel replacement with natural gas and the energy charge of these replacement is studied. The following data are presented: data on the consumption of vaporous (gaseous superheated) natural gas (hereinafter gaseous natural gas) during field operation of gas-diesel BelAZ 75131 mining dump trucks; flow rate of gaseous natural gas in pipelines; consumption of antifreeze at the inlet to the liquefied natural gas evaporator, as well as antifreeze temperature at the inlet and outlet of the evaporator; temperature of gaseous natural gas at the outlet of the reducer after the evaporator; data on the comparison of temperature profiles in the cylinders of CUMMINS KTA 50 internal combustion engine under diesel and gas-diesel operation.
\end{abstract}

\section{Introduction}

Vehicles are a heavy consumer of fuel and energy resources, accounting for about $13 \%$ of them. Conventional internal combustion engines using liquid petroleum fuel are the predominant type of propulsion systems in road and waterborne vehicles. The specific consumption of liquid petroleum fuel by freight road transport is annually decreasing. This is due to the modernization of vehicles through the introduction of new highly efficient in-

\footnotetext{
*Corresponding author: nikokem@mail.ru
} 
ternal combustion engines running on alternative energy carriers [1]. Nevertheless, the problem of saving liquid petroleum energy carriers remains acute.

Russia has large reserves of high-quality motor fuel that does not require any chemical processing to be used in engines. This fuel is primarily natural gas. As a motor fuel, natural gas is superior to fuel oil in its natural form. Internal combustion engines have high cost-performance ratio, since natural gas has good antiknock properties, favorable conditions for carburetion and wide ranges of ignition in a mixture with air.

Natural gas is mainly composed of methane mixed with other hydrocarbons and inert gases. In the 80 s of the last century, the Italian company Tessari was one of the first to convert a $100 \mathrm{~kW}$ diesel engine to gas-diesel operation. Tests were carried out at $20 \%$ diesel and $80 \%$ natural gas consumption at rated load.

The properties of gas as a motor fuel can be divided into three groups:

- motor properties (properties that determine the combustion and the entire process of internal combustion engine operation);

- properties that determine the operation of the fuel equipment of a motor vehicle;

- properties that determine the conditions of fuel production and its delivery to the consumer.

The main factors determining the performance of gas motor fuel are the properties of the first group. But other properties are not unimportant, as they determine design and engineering solutions. The motor properties of fuel mainly depend on the heat of gas combustion.

In practice, natural gas as a motor fuel is used in compressed or liquefied states. The main consumers of compressed natural gas $(\mathrm{CNG})$ are cars and light-duty trucks. The main consumers of liquefied natural gas (LNG) are water-borne vehicles, public service road vehicles, agricultural vehicles and mine haulage trucks [2-7].

The worldwide growth in coal consumption and, consequently, in the volume of open pit mining leads to an obvious increase in the need in mining equipment that provides high economic and environmental performance [8]. The complication of the operating conditions of mining equipment associated with an increase in the productivity of mining operations causes an increase in its concentration in a limited space, which means an increase in the emissions of harmful substances contained in the exhaust gases into the atmosphere. The intensification of open pit mining leads to an increase in the consumption of diesel fuel by mining dump trucks. Millions of tons of diesel fuel are consumed annually, with $70-80 \%$ of the total fuel consumed by loaded dump trucks on slopes at low speeds. This leads to significant emissions of harmful substances into the atmosphere, including $\mathrm{CO}^{2}$, which is one of the main greenhouse gases effecting global warming [2, 9].

The main type of vehicles for rock mass hauling are dump trucks [10-14]. BelAZ mining dump trucks with diesel internal combustion engines are the most widespread in Russia. The fleets of open-pit mining companies are mainly equipped with mining dump trucks of the BelAZ-75131 model and their modifications $[15,16]$.

Taking into account the increasing environmental and economic requirements for open pit mining, projects are being implemented to design new mining equipment (environmentally friendly and cost-efficient) and modernize the existing one [1]. One of such projects is the successfully implemented project of the conversion of BelAZ mining dump trucks to dual-fuel gas-diesel operation. The project was implemented by the companies LLC Resurs (Russia, Novokuznetsk), LLC Sibir-Energo (Russia, Novokuznetsk), LLC TechnoEko (Russia, Prokopyevsk) with technical and scientific support of OJSC BELAZ - the managing company of BELAZ-HOLDING (Zhodino, Belarus); LLC KAMSS (Russia, Novokuznetsk); KuzSTU (Russia, Kemerovo). During the implementation of the pro- 
ject, 60 BelAZ 75131 mining dump trucks with CUMMINS KTA 50 internal combustion engine were converted to gas-diesel operation and successfully put into operation [17-20].

Considering the novelty and practical value of the implemented project, the issue of conducting research aimed at identifying key performance indicators of gas-diesel BelAZ 75131 mining dump trucks is urgent. In this regard, the purpose of the presented work is study and comparative analysis of fuel consumption and temperature characteristics of CUMMINS KTA 50 internal combustion of engine BelAZ 75131 mining dump trucks equipped with an on-board cryogenic fuel system.

\section{Materials and Methods}

Measurements and comparative analysis of fuel consumption and temperature characteristics of CUMMINS KTA 50 internal combustion engine of BelAZ 75131 mining dump truck equipped with an on-board cryogenic fuel system (hereinafter the BelAZ engine) were carried out at the engine speed range of 650-1950 rpm. When conducting research under various operating conditions, the following parameters were recorded: total consumption, as well as consumption of gaseous natural gas in the right and left bank cylinders of internal combustion engine; gaseous natural gas consumption in the pipelines after the injector racks; flow rate of the coolant (antifreeze) at the evaporator inlet; antifreeze temperature at the inlet and outlet of the evaporator; average air velocity in the right and left pipelines; temperature of gaseous natural gas at the outlet of the reducer after the evaporator; temperatures in the cylinders of CUMMINS KTA 50 internal combustion engine under diesel and gas-diesel operations.

Antifreeze consumption was determined by an ultrasonic flow meter "Portaflow $220 \mathrm{~A} "$, and its temperature at the inlet and outlet of the evaporator was determined by temperature sensors. The air velocities in the left and right pipelines after the injector racks were determined using a TESTO-512 differential pressure gauge and Pitot-Prandtl tubes. Standard thermocouples were used to measure the temperatures of gases expelled from the cylinders and reflecting the operating temperature in the cylinders of CUMMINS KTA 50 internal combustion engines of BelAZ 75131 mining dump trucks.

Gas flow meters 6, 7 with an electronic unit, manufactured by the authors, were installed on each pipeline for supplying gaseous natural gas to determine the instantaneous consumption of natural gas [8]. Further, after passing differential pressure gauges DD1, DD2 (TESTO-512) with Pitot-Prandtl tubes, gas entered the air intakes 8,9 of the right and left banks of cylinders of CUMMINS KTA 50 internal combustion engine. The connection diagram is shown in Fig. 1. A gas pressure pulsation damper 4 was installed after the injector racks 1, 2 to ensure high-quality measurement of the flow rate (Fig. 2).

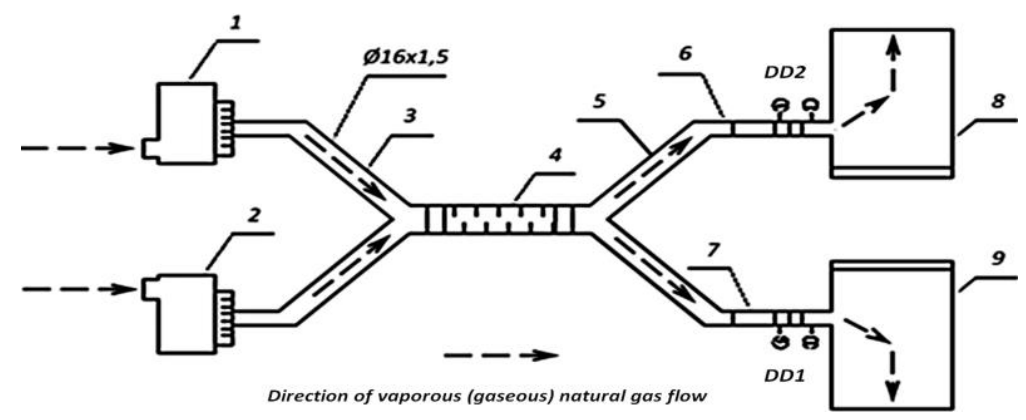

Fig. 1. Diagram of the supply of gaseous natural gas from the injector racks to the air intakes of the CUMMINS KTA 50 internal combustion engine 


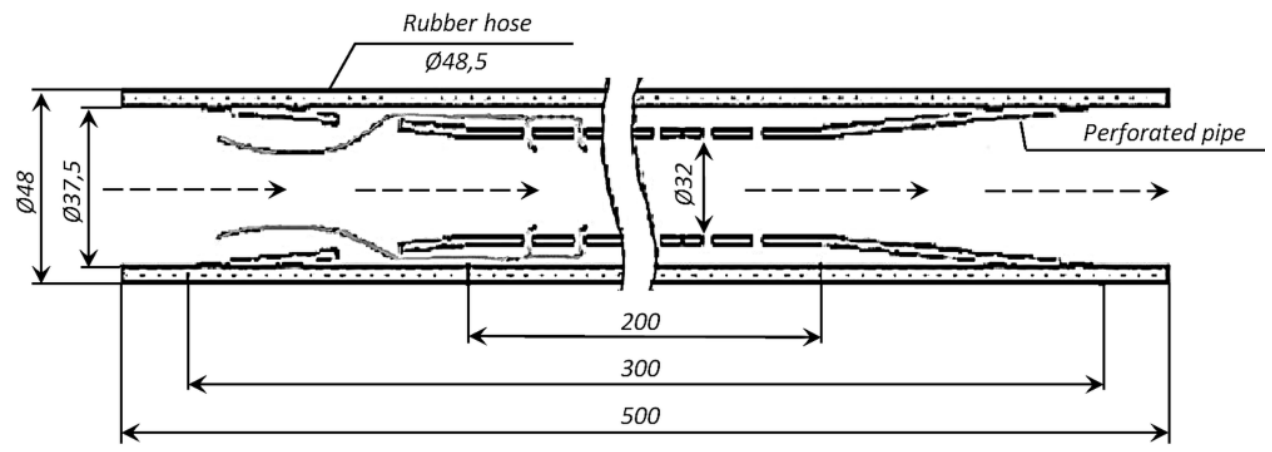

Fig. 2. Gaseous natural gas pressure pulsation damper

\section{Results and Discussion}

At the initial stage of the research, a prerequisite was to determine the relationship between the ratio of diesel fuel replacement with natural gas and the energy charge of these replacement. This is primarily due to cost effectiveness requirements, that is, ensuring the necessary and sufficient volume of natural gas supply to CUMMINS KTA 50 internal combustion engine during the operation of a mining dump truck in order to prevent the loss of its power. Also, the determination of the necessary and sufficient volume of natural gas allows preventing gas losses due to underburning in the event of gas excess in the combustion chamber, as well as minimizing overheating of CUMMINS KTA 50 internal combustion engine during its operation.

The relationship between the natural (mass or volumetric) ratios of diesel fuel replacement with natural gas and the energy charge of these replacements is shown in Fig. 3.

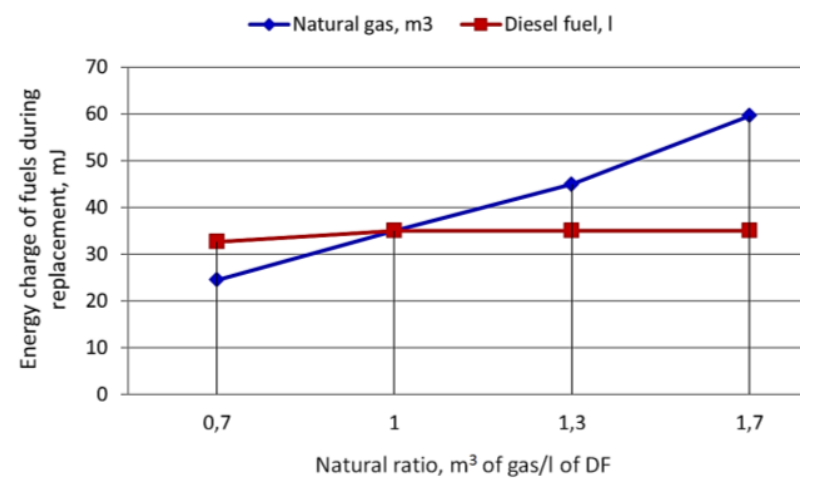

Fig. 3. Relationship between natural ratios of diesel fuel replacement with gaseous natural gas and the energy charge of these replacement

As shown by the relationship in Fig. 3, the same energy replacement corresponds to natural replacement equal to 1.0 . In this case, there is an adequate replacement of the energy charge of diesel fuel with natural gas. It is obvious that gas-diesel operation of CUM-MINS KTA 50 internal combustion engine will provide cost-performance ratio that corresponds to datasheet specifications for diesel-only operation. In other words, according to the energy charge criterion, one liter of diesel fuel must and should be replaced with one cubic meter of natural gas. The graphs shown in Fig. 3 also indicate that with a 
displacement ratio of less than 1.0, the engine will operate on a lean mixture, and with a ratio of more than 1.0, on a rich mixture during normal operation of the air turbine. In the first case, this will lead to a loss of the power of internal combustion engine, and in the second case, there will be a significant overconsumption of natural gas, and, as a consequence, a decrease in cost-performance ratio of the operation of mining dump trucks.

Figures 4, 5 show the dependences of the values of the antifreeze flow rate at idle through the evaporator, as well as the air velocities in the left and right pipelines, at which it is supplied to the turbine, when the speed of CUMMINS KTA 50 internal combustion engine changes. As the results of the measurements showed, with an increase in the CUMMINS KTA 50 internal combustion engine speed from 650 to $1950 \mathrm{rpm}$, there is an increase in both the antifreeze flow rate passing through the evaporator from 46.08 to 124 $1 / \mathrm{min}$ and the average air velocities, at which it is supplied to the turbine, in the right and left pipelines from 3.81 to $11.6 \mathrm{~m} / \mathrm{s}$ and from 3.98 to $11.73 \mathrm{~m} / \mathrm{s}$, respectively. It should be noted that the air velocities in both the left and right pipelines differed a little in their values.

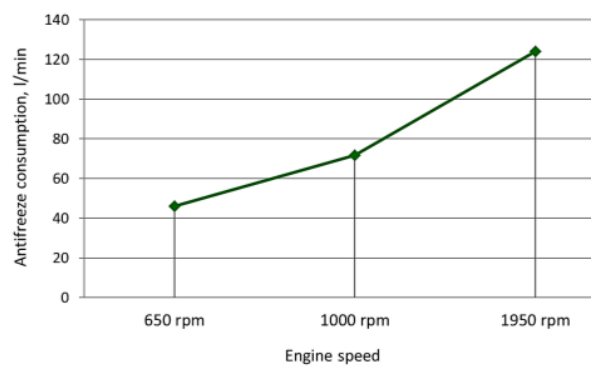

Fig. 4. Antifreeze consumption depending on the speed of CUMMINS KTA 50 internal combustion engine

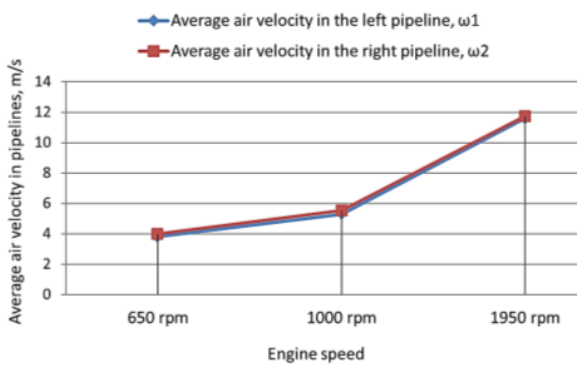

Fig. 5. Air velocities in the left and right pipelines of CUMMINS KTA 50 internal combustion engine

The liquefied natural gas consumption at the inlet to the evaporator, which is an integral part of the cryogenic fuel system, was determined from the heat balance equation, assuming that the heat transferred from the antifreeze is spent on the transition of liquefied natural gas to the state of dry saturated vapor of the mixture and its overheating at constant pressure. The scheme of flows in the evaporator is shown in Fig. 6.

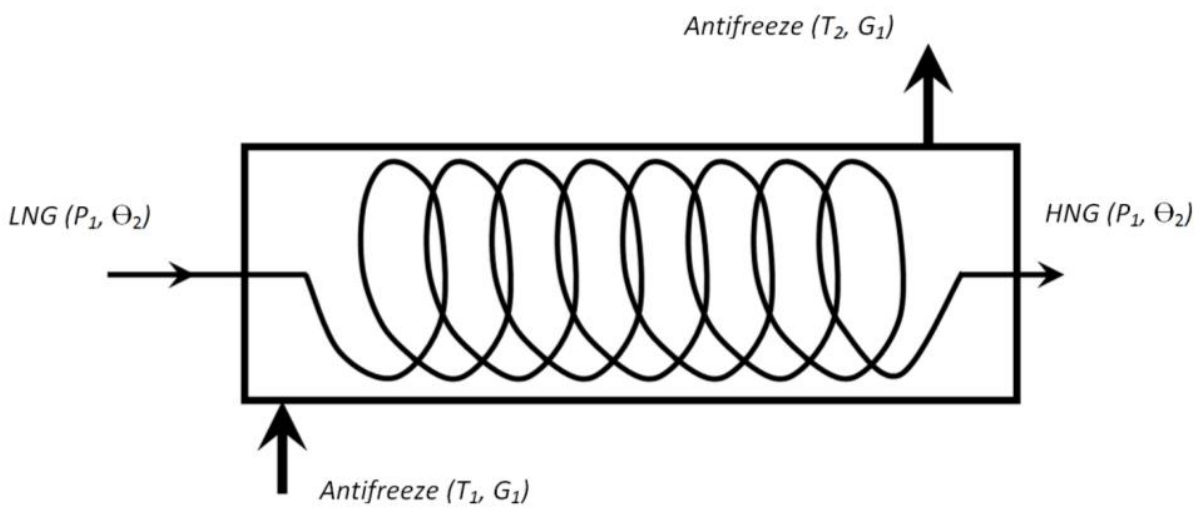

Fig. 6. Scheme of coolant (antifreeze) and liquefied natural gas (LNG) flows in the evaporator 
Based on the results of the measured parameters, the amount of heat transferred from the antifreeze to liquefied natural gas was determined according to the equation:

$$
Q_{1}=G_{1} c_{\mathrm{p} 1}\left(T_{1}-T_{2}\right)=1.378 \cdot 3.82(366.89-365.84)=5,527 \mathrm{~kW} ;
$$

The thermodynamic parameters of liquefied natural gas at the inlet to the evaporator were determined by the readings of a pressure gauge installed on the cryogenic fuel tanks (tanks for storing liquefied natural gas). The calculation was carried out at a speed of internal combustion engine CUMMINS KTA of 50-1200 rpm.

The temperature of liquefied natural gas at the inlet to the evaporator was unknown; to determine it, the $i-T$ dependence - a diagram according to the experimental data of N.V. Pavlovich - was used.

It was assumed that the pressure of liquefied natural gas at the inlet to the evaporator and the gas pressure at the outlet of it are the same, that is:

$$
P_{1}=P_{2}
$$

Heat $Q_{1}$, given to liquefied natural gas can be consumed:

- in case of subcooling, for heating the liquefied gas to the boiling point at the corresponding pressure:

$$
Q_{2}=G c_{\mathrm{i}}\left(\theta_{2}-\theta_{1}\right)
$$

- on the phase transition of gas from the liquid to the vapor (gaseous) state $Q_{3}$ at the temperature $\theta_{2}$ :

$$
Q_{3}=G\left(i^{\prime \prime}-i^{\prime}\right)
$$

- for gas overheating to the temperature $\theta_{3}$, equal to the temperature at the outlet of the evaporator $Q_{4} \Theta 3$,:

$$
Q_{4}=G c_{\mathrm{pg}}\left(\Theta_{3}-\theta_{2}\right)
$$

Since there were no reliable data on the temperature $\theta_{3}$, it was assumed that liquefied natural gas is supplied to the evaporator at the boiling point $\theta_{2}$, therefore, $\theta_{2}$ was not taken into account in the calculations. The gas enthalpy at the temperature of superheating and of the saturated liquid was determined from the $i-T$ diagram of N.V. Pavlovich.

The gas mass flow rate $G$ was determined from the heat balance $Q_{1}=Q_{3}+Q_{4}+Q_{p o t}$, taking into account that the external heat loss is $3-5 \%$ of $Q_{1}$, according to the following relationship:

$$
\begin{gathered}
G=0,95 \cdot Q_{1} /\left(i^{\prime}-i^{\prime}\right)+c_{\mathrm{pg}}\left(\Theta_{3}-\Theta_{2}\right)= \\
=0.95 \cdot 5.527 /(-80-(-176)) \cdot 4.19+2.23 \cdot(45-(-115))=0.0069 \mathrm{~kg} / \mathrm{s}
\end{gathered}
$$

Field studies of consumption characteristics of CUMMINS KTA 50 internal combustion engine were carried out simultaneously recording the following parameters: speed of internal combustion engine, consumption of the antifreeze, temperature of the antifreeze at the inlet and outlet of the evaporator, gaseous natural gas consumption and flow velocity in the pipeline after the injector racks. These dependences are shown in Fig. 7-8 


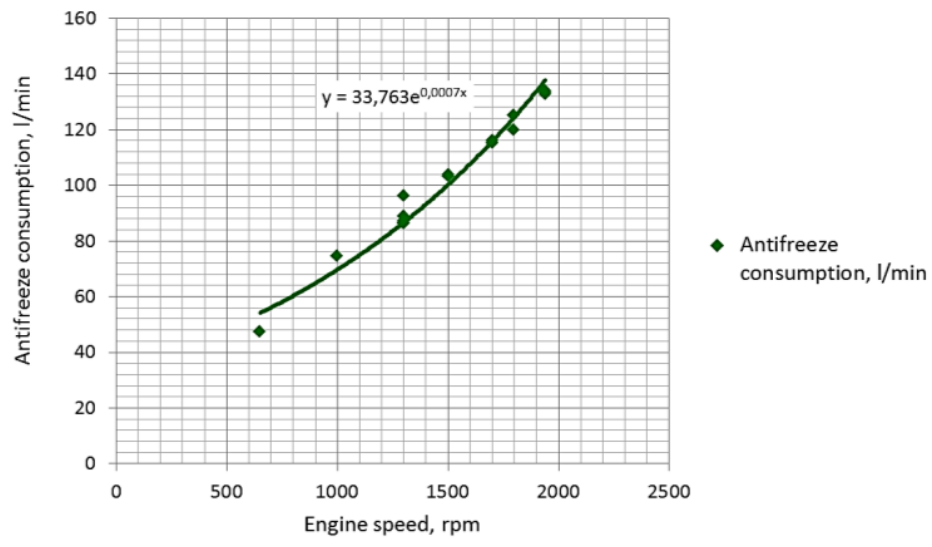

Fig. 7. Antifreeze consumption depending on the speed of CUMMINS KTA 50 internal combustion engine and operating conditions

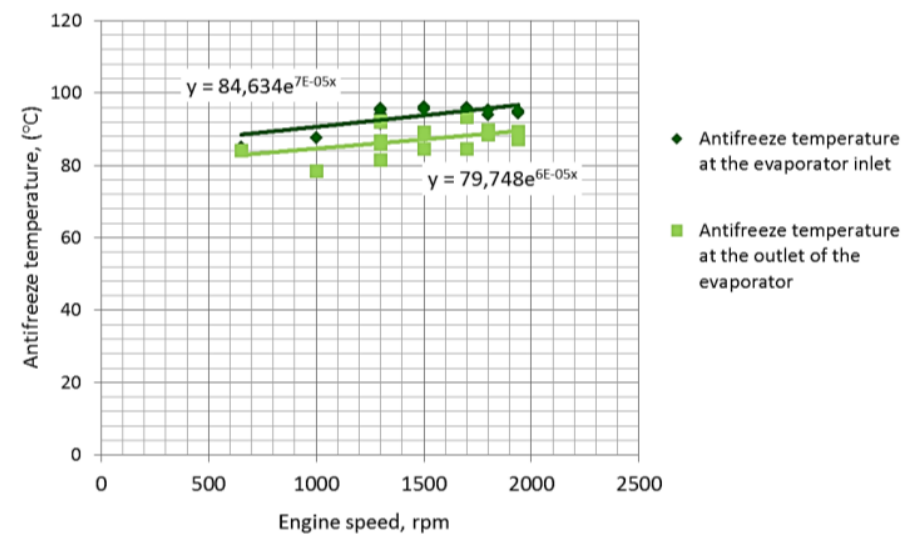

Fig. 8. Antifreeze temperature at the inlet and outlet of the evaporator depending on the speed of CUMMINS KTA 50 internal combustion engine and operating conditions

The dependence in Fig. 7 indicates that with an increase in the speed of internal combustion engine, the antifreeze consumption increases from 47 to $133 \mathrm{l} / \mathrm{min}$. In idling mode, CUMMINS KTA 50 internal combustion engine runs on diesel fuel only, so there is no natural gas consumption. The graphs in Fig. 8 indicate that the average value of the antifreeze temperature difference at the inlet and outlet is $6.6^{\circ} \mathrm{C}$. This fact confirms the efficiency of the developed evaporator design, which uses the coolant of a mining dump truck - antifreeze.

With the complication of operating conditions when the loaded BelAZ 75131 mining dump truck is going uphill, and with the consequent increase in the speed of CUMMINS KTA 50 internal combustion engine, the velocity of gaseous natural gas flow through the pipelines after the injection racks, and accordingly, its consumption increases proportionally. This, in turn, indicates that mining dump trucks equipped with a cryogenic fuel system are the most cost-effective when operating in difficult sections of mine workings with steep slopes, where the maximum load on the internal combustion engine occurs and, accordingly, there is the maximum consumption of natural gas, replacing diesel fuel. In addition, the environmental issue is also an important point. The maximum consumption of diesel fuel is known to occur in difficult sections of mine workings, when a dump truck 
goes uphill, where, among other things, there is a maximum emission of harmful substances with exhaust gases, which leads to gas and smoke pollution of industrial sites, especially in winter.

The dependencies in Fig. 9 indicate that with the increasing complexity of operating conditions, accompanied by an increase in the speed of CUMMINS KTA 50 internal combustion engine, the natural gas glow rate in each bank of cylinders increases proportionally. Moreover, it should be noted that the average difference in the readings of the gaseous natural gas flow rate between the banks of cylinders did not exceed $1.2 \mathrm{~m}^{3} / \mathrm{h}$. This is obviously due to the technical condition of CUMMINS KTA 50 internal combustion engine, including the condition of its piston system, as well as some measurement errors. These dependences also indicate that with an increase in the speed of internal combustion engine, the difference in the gaseous natural gas flow rate between the banks of cylinders is significantly reduced.

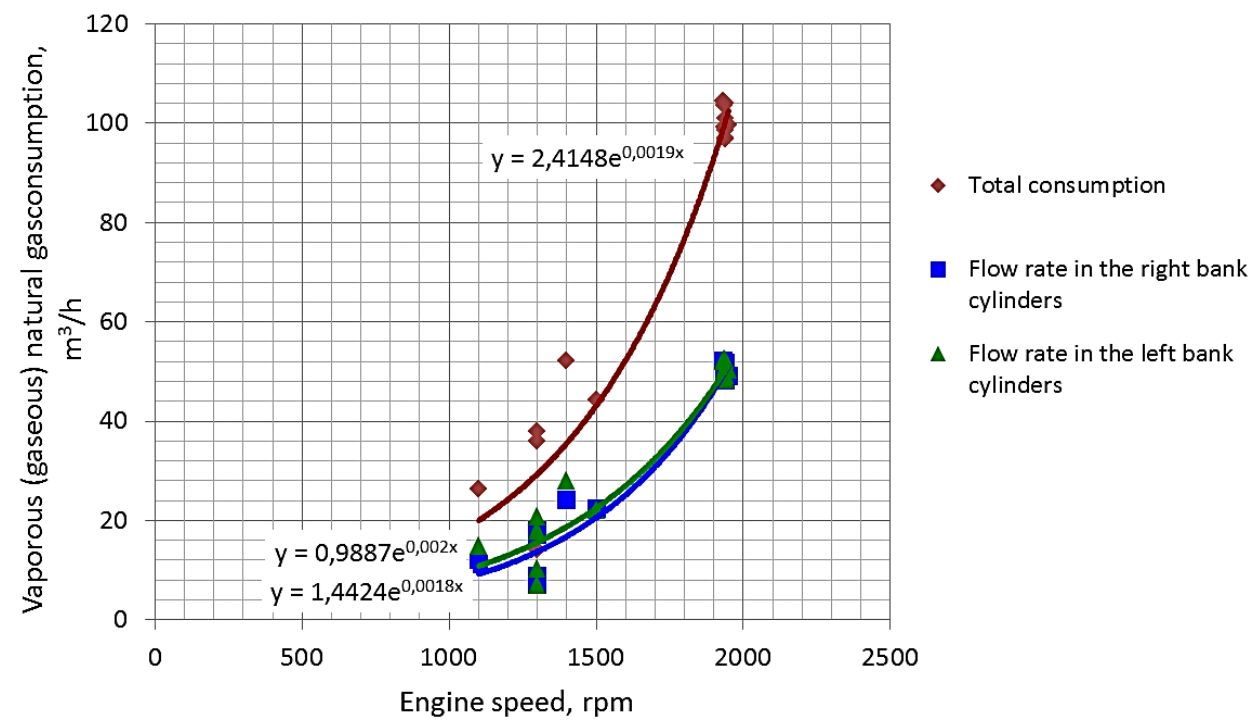

Fig. 9. Consumption of gaseous natural gas depending on the speed of CUMMINS KTA 50 internal combustion engine and operating conditions

An important part of the research was the measurement and comparison of the temperature profiles in the cylinders when CUM-MINS KTA 50 internal combustion engine was running on diesel and gas-diesel fuels. The measurements were carried out on the coal mine haulage road along the same route in September at an ambient temperature of $+18^{\circ} \mathrm{C}$. During measurements, BelAZ 75131 gas-diesel mining dump truck ran at the maximum engine speed $n=1940-1950 \mathrm{rpm}$. Antifreeze consumption varied in the range of $129.9-133 \mathrm{l} / \mathrm{min}$. The flow meter readings for the gaseous natural gas consumption in the right and left banks of cylinders were 62 and $59 \mathrm{~m}^{3} / \mathrm{h}$, respectively. The average gas temperature after the evaporator at the outlet of the reducer was $+35^{\circ} \mathrm{C}$. The gas pressure after the reducer is 4.89 ata. The engine ran steadily. The pressure drop between the turbines was normal. The recorded values of the temperatures of gases expelled from the cylinders, reflecting the temperature in the cylinders when operating on diesel and gas-diesel fuel, are shown in Fig. 10-13.

As the results of the studies have shown, diesel and gas-diesel operations of CUMMINS KTA 50 internal combustion engine differ in temperature and its uniformity in the cylinders. So, diesel-fuelled operation of the engine is accompanied by an uniformity of 
temperature values, both in the left and in the right banks of cylinders. Under gas-dieselfuelled operation, such uniformity is not observed, which is confirmed by a decrease in the spread of points on the graph. This suggests that the use of natural gas as a motor fuel leads to a more uniform temperature profile of the internal combustion engine operation. However, under gas-diesel-fuelled operation, a slight increase in the temperature by an average of $10-15^{\circ} \mathrm{C}$ is observed. This slight increase in the temperature cannot critically affect the operation of CUMMINS KTA 50 internal combustion engine.

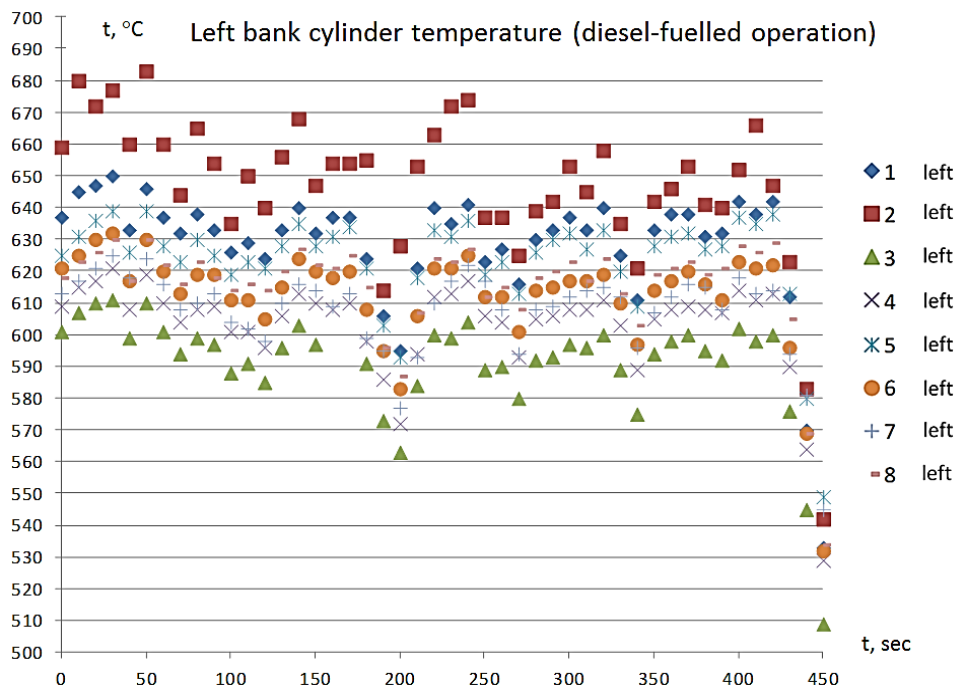

Fig. 10. Temperature in the left bank cylinders under diesel-fuelled operation of BelAZ 75131 mining dump truck (September, $\mathrm{t}_{\mathrm{amb}}+18^{\circ} \mathrm{C}$ )

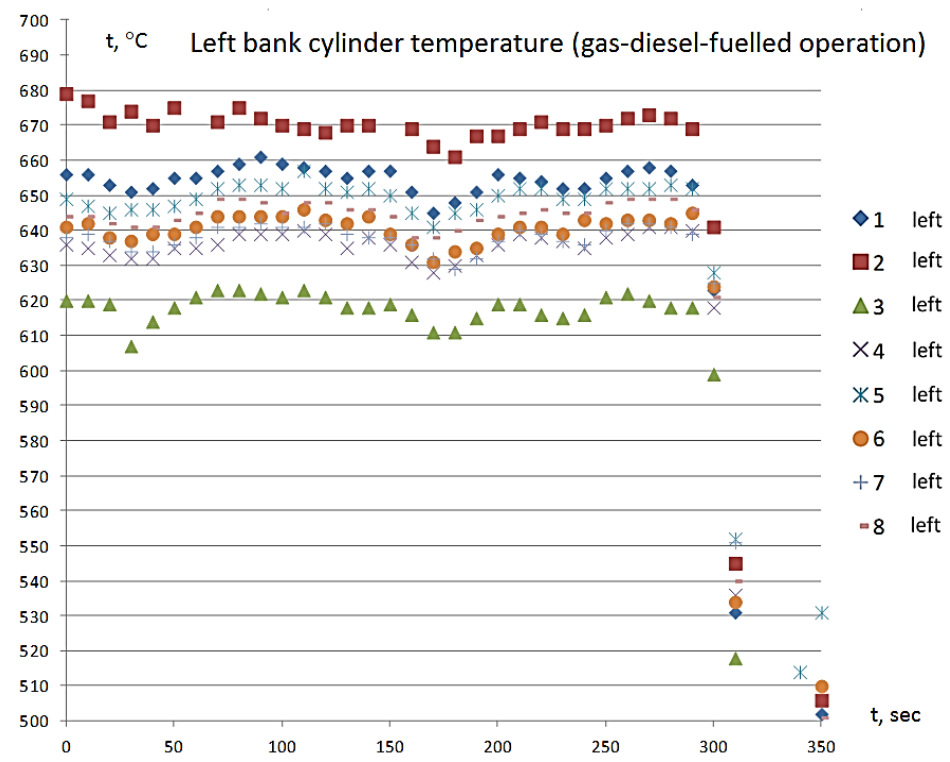

Fig. 11. Temperature in the left bank cylinders under gas-diesel-fuelled operation of BelAZ 75131 mining dump truck (September, $\mathrm{tamb}_{\mathrm{amb}}+18^{\circ} \mathrm{C}$ ) 


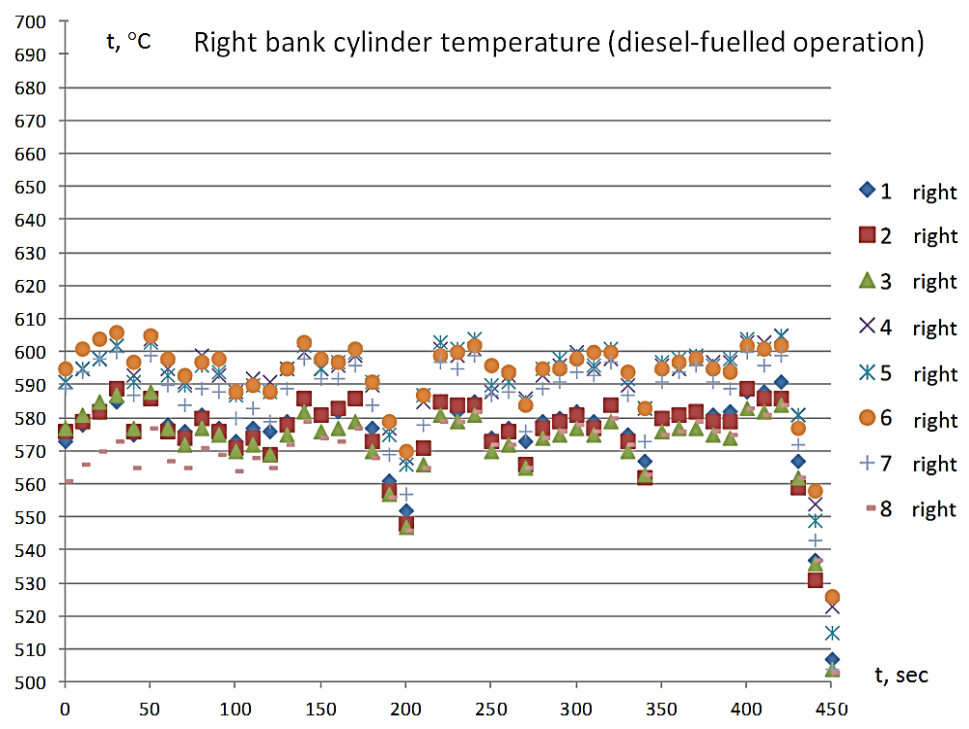

Fig. 12. Temperature in the right bank cylinders under diesel-fuelled operation of BelAZ 75131 mining dump truck (September, tamb $+18^{\circ} \mathrm{C}$ )

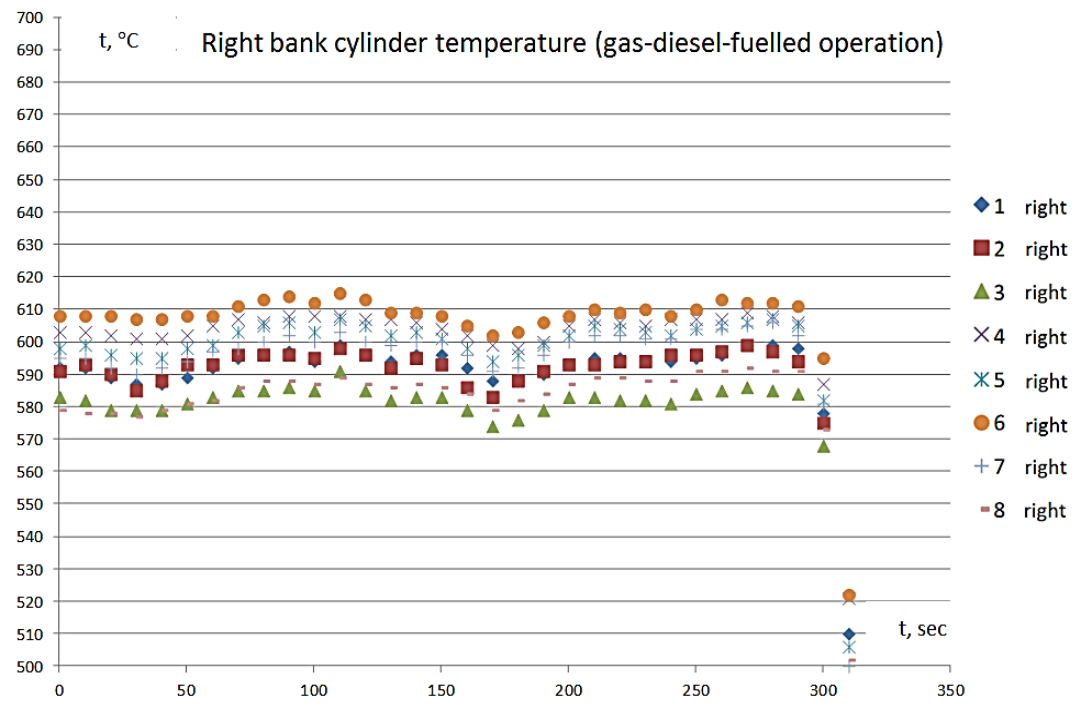

Fig. 13. Temperature in the right bank cylinders under gas-diesel-fuelled operation of BelAZ 75131 mining dump truck (September, $\mathrm{t}_{\mathrm{amb}}+18^{\circ} \mathrm{C}$ )

\section{Conclusion}

The results of the study of fuel consumption and temperature characteristics of CUMMINS KTA 50 internal combustion engines of gas-diesel BelAZ 75131 mining dump trucks made it possible to draw the following conclusion:

1. The developed methods of study of fuel consumption and temperature characteristics, as well as a technique of measuring the flow rate of vaporous (gaseous) natural gas, 
including a gas pulsation damper specially designed for these purposes, made it possible to conduct the necessary qualitative and quantitative field research at mine workings.

2. Study of the relationship between the ratio of diesel fuel replacement with natural gas and the energy charge of these replacement showed that an economically feasible ratio of diesel fuel replacement with gaseous fuel should be considered a value of no more than 1.0 , i.e. $1 \mathrm{~m}^{3}$ of natural gas is necessary and sufficient to replace 1 liter of diesel fuel.

3. Under production conditions, with an increase in the speed of CUMMINS KTA 50 internal combustion engine from 650 to $1940 \mathrm{rpm}$, the flow rate of antifreeze passing through the evaporator of the cryogenic on-board fuel system increases proportionally from 47 to $134 \mathrm{l} / \mathrm{min}$

4. The average value of the readings of the antifreeze temperature difference at the inlet and outlet of the evaporator was $6.6^{\circ} \mathrm{C}$, which confirms the effectiveness of the layout and design solution of the developed and implemented evaporation system (evaporator) of the cryogenic onboard fuel system.

5. The consumption of gaseous natural gas does not depend on the load (laden, empty) of BelAZ 75131 gas-diesel mining dump truck. The consumption of gaseous natural gas depends on the speed of the internal combustion engine, its movement (in a straight line, uphill, downhill) and the driving features.

6. Gas-diesel operation of BelAZ 75131 mining dump trucks, in relation to the diesel-fuelled operation, is accompanied by more uniform and constant temperatures for each bank of cylinders with a relatively small overall increase, on average by $10-15^{\circ} \mathrm{C}$, which does not critically affect the operation of CUMMINS KTA 50 internal combustion engine.

7. From an environmental and economic point of view, BelAZ 75131 gas-diesel mining dump trucks are most effective in operation on difficult sections of mine workings with steep slopes, where the maximum load on internal combustion engines occurs and, accordingly, there is a maximum consumption of natural gas that replaces diesel fuel.

8. The results of the study of fuel consumption and temperature characteristics of CUMMINS KTA 50 internal combustion engine of gas-diesel BelAZ 75131 mining dump trucks showed viability and competitiveness of this type of mining equipment in relation to diesel-fueled transport when operating in difficult conditions of mining sites.

\section{References}

1. G.M. Dubov, D.S. Trukhmanov, S.A. Nokhrin, IOP Conf. Series: Earth and Environ. Sci., 459, 042059 (2020)

2. M.L. Khazin, PJPME, vol. 19, 1, 56 (2019)

3. J.L. Osorio-Tejada, E. Llera-Sastresa, S. Scarpellini, Renew. Sust. Energ. Rev., 71, 785 (2017)

4. V.Y. Koptev, A.V. Kopteva, IOP Conf. Ser.: Earth Environ. Sci., vol. 87, 2, 022010 (2017).

5. K. Cheenkachorn, C. Poompipatpong, C.G. Ho, Energy, 53, 52 (2013)

6. H.A.A. Wahhab, M.A. Ismael, A. Aziz, M.R. Heikal, AJAS, 10(2), 88 (2017)

7. S.S. Azikhanov, A.R. Bogomolov, G.M. Dubov, S.A. Nokhrin, MATEC Web Conf., 297, 03001 (2019)

8. G.M. Dubov, D.S. Trukhmanov, A.A. Chegoshev, V.E. Ashikhmin, E3S Web Conf., 41, 03008 (2018)

9. D.A. Chernetsov, Eff. J. Prob. Cont. Sci. Prac. Vernad. Univ, 10-12, 54 (2010)

10. G.M. Dubov, D.S. Trukhmanov, S.A. Nokhrin, A.N. Sergel, MATEC Web Conf., 297, 03002 (2019)

11. E. Kuzin, V. Bakin, D. Dubinkin, E3S Web Conf., 41, 03020 (2018) 
12. A.B. Kartashov, B.B. Kositsyn, G.O. Kotiev, S.V. Nazarenko, D.M. Dubinkin, E3S Web Conf., 174, 03009 (2020)

13. A.B. Kartashov, B.B. Kositsyn, G.O. Kotiev, D.M. Dubinkin, S.V. Nazarenko, Mining Equipment and Electromechanics. 3, 11 (2020)

14. D.M. Dubinkin, A.B. Kartashov, G.A. Arutyunyan, N.V. Buzunov, K.P. Sorokin, A.V. Yalyshev, Mining Equipment and Electromechanics, 6, 31 (2020)

15. I.V. Kuznetsov, I.A. Panachev, G.M. Dubov, S.A. Nohrin, Handbook. An Engineering journal, 4, 265 (2019)

16. I.V. Kuznetsov, I.A. Panachev, G.M. Dubov, S.A. Nohrin, E3S Web Conf., 174, 03010 (2020)

17. G.M. Dubov, D.S. Trukhmanov, I.V. Kuznetsov, S.A. Nokhrin, A.N. Sergel, E3S Web Conf., 105, 03019 (2019)

18. G.M. Dubov, D.S. Trukhmanov, S.A. Nokhrin, A.N. Sergel, E3S Web Conf., 174, 03016 (2020)

19. S.A. Nohrin, G.M. Dubov, D.S. Trukhmanov, Patent 2701133 (The Russian Federation, 2019)

20. G.M. Dubov, D.S. Trukhmanov, I.V. Kuznetsov, S.A. Nokhrin, A.N. Sergel, E3S Web Conf., 105, 03018 (2019) 